\title{
The Relative Status \\ Of Transactional And Transformational Leadership - Question Of Balance
}

Grant Jones, (E-mail: grant.jones@mgsm.edu.au), Macquarie University, Australia,

\begin{abstract}
Validation studies tend to give primacy to transformational leadership, but if leadership is focused of issues of sustainability rather than change, then transactional leadership may be accorded greater status.
\end{abstract}

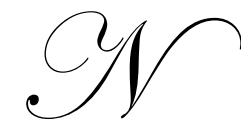

ormative theories deserve particular scrutiny because they, in fact, recommend particular types of leadership behaviour and they presuppose particular types of performance. They make the case that if you adopt behaviour X you will get outcome Y. Companies seeking to make an investment in training and development find normative theories attractive because they promise a measurable outcome and it is that outcome that attracts the organisation to the training. The more a particular leadership model is focused on outcomes that are valuable to industry the more readily consultants around the world pick up and promote that particular model and its associated assessment technology.

A normative, behaviourally focused, leadership theory that has enormous currency in the world today is Bass and Avolio's five factor leadership model (see Bass 1990; Bass and Avolio 1993). The model has been franchised around the world as a questionnaire based leadership assessment and development tool. The results of each leadership assessment are linked to a coaching program designed to increase the frequency of desirable leadership behaviours in day-to-day workplace interactions and decrease the frequency of undesirable actions. As such, the constructs, the results and the behavioural modification program are highly normative and highly prescriptive. The essential question then becomes: are these the right prescriptions for leadership? This question becomes more pressing, once the achievement of Bass and Avolio in harnessing leadership education and training to its central concepts is understood.

Leadership is an area that is replete with theories and models. Some models tend to be purely descriptive, providing a picture of how leadership is practiced. An example of such a descriptive model would be the classic distinction between task focused and relationship/people focused leader behaviours that had its genesis the Michigan and the Ohio State studies. Behaviourally based theories carry with them the possibility that certain behaviours can be selected as desirable and their desirability can be validated by observational research. So it is that Blake and Mouton (1978) took the basic constructs of task and relationship focused behaviour and turned them into a prescriptive model that tells us all exactly how task and relationship focused we are to be. Validation studies of behavioural prescriptions for leadership choose a set of intrinsically desirable organisational outcomes and provide statistical correlations between the selected leadership behaviours and those outcomes. Each model and each set of outcomes is underpinned by a set of values that prescribe what leadership should be and the ends to which it should be put. Thus, theories linking leadership to productivity tend to be normative, which is to say they try to intervene in the practice of leadership and change the common practice to fit a particular set of behaviours and imperatives.

In doing so, they can lose sight of other, perhaps equally important, imperatives. This problem was partly addressed by the so-called "situational leadership" which argued that there is no one best way to lead, but rather that managers should make assessments of the situations that they face and develop a leadership style appropriate to each situation. These theories suggested situational variables such as worker maturity (Hersey and Blanchard 1988) or the favourability of the managerial situation from the manager's perspective, where favourability is defined in terms 
of the structure of typical tasks, the power possessed by the leader and the quality of relationships between leaders and members (Feidler 1984).

In focusing on the situational variables these theorist tended to be more open on the question of exactly what constituted leadership performance. In situational theories the type of performance required does not drive leadership behaviour; instead, recommended leader behaviour is determined by the situational constraints and capacities faced by managers. If situational theories can be critiqued, it is for not being explicit about the different kinds of leadership performance that are required by different organisations.

Bass and Avolio's five factor model and its associated assessment instrument, the Multi-factor Leadership Questionnaire (MLQ) is a highly normative model. The model has credibility among academics, who are impressed by the massive citation that Bass and Avolio have received and the huge research effort that has gone into validating the link between the recommended leader behaviours and actual workplace performance. However, it is also highly credible among management and leadership consultants. Testament to this credibility is the fact that Bass and Avolio have franchised the technology to consultants around the world.

The two most important concepts of leadership underpinning the five factor model are those of "transformational" and "transactional" leadership. As the terms suggest transformational leadership is the kind of leadership that inspires people to change. In fact it taps directly into the idea of leader as change agent that has been promoted by leading academics in the Harvard Business School such as Kotter (1999) and Heifetz (2001). The elements of transformational leadership that are tested by the MLQ include charisma, the leader's capacity to provide intellectual stimulation to others and the leader's capacity to understand and respond to individual differences in others.

Transactional leadership is much more pedestrian. In fact Kotter and Hefietz would not call it leadership at all but classify it as mere management. Transactional leadership involves the maintenance of order and due process. Its behavioural features include "management by exception" and "contingent reward." Management by exception relates to the leaders ability to correct deviations from accepted protocols or routines by others. "Contingent rewards" involves a simple administrative process of measuring people's output/outcomes and providing rewards. The questionnaire asks how often a particular leader exhibits transformational behaviours and transactional behaviours.

With the focus of transformational leadership on inspirational and visionary change and the focus of transactional leadership on compliance, it is not difficult to imagine which style of leadership and which form of assessment is going to be most attractive to both the leaders being assessed and the organisations doing the assessing. Bass and Avolio actually endorse a hierarchy which places transformational leadership above transactional leadership. The most recent version of the standardised reports that their franchisees produce after processing the results of the MLQ actually provides ideal bands based on the classic likert scale. On a scale of one to five the ideal they recommend for transformational leadership is between 3 and 3.75, whereas the ideal for transactional leadership is between 1 and 2 against the management by exception behaviour and between 2 and 3 for the contingent reward behaviour. The normative statement is that it's good to be highly transformational and not very transactional.

Much of the research literature supports this hierarchy. Typically this literature relates transformational literature to high performance by associating samples of transformational leadership with the achievement of significant change in the respective work places examined (see for example Yammarino, Spangler and Bass 1993; Howell and Avolio 1993; Barratt, Hollway and Shergold 1996; Den Hartog, Van Muijen and Koopman 1997; Kilpatrtick and Lock 1996; Lowe, Kroeck, and Sivasubramaniam, 1996; Barling, Weber, and Kelloway, 1996; Russ, McNeilly and Comer 1996). There is also research to associate transformational leadership with human relations style outcomes such as satisfaction, commitment, trust and behaviours generating corporate spirit and citizenship (McNeese Smith 1996; Podsakoff, McKensie and Bommer 1996). Lowe, Kroeck, and Sivasubramaniam, 1996). 
These kinds of leadership outcomes and the transformational leadership that supports them are likely to be popular in an environment of hypercompetition, whereby change is continuous and unpredictable. In such an environment it might be supposed that the importance of transactional leadership can be overlooked or even relegated as Bass and Avolio have done. Clearly the leader's career can be made by identifying and building into his or her style transformational behaviours that can be recognised by others and can effect achievements in organisational change.

However, careers that can be made by achieving innovative change can be just as easily destroyed by failure to impose process. A spectacular example is the case of Frank Cicutto. When Mr Ciccuto had begun his career 37 years before his fall at a local branch of the National Australia career progress had been slow and based on seniority. However, with the deregulation of the 1980s National Australia Bank, the capacity to show entrepreneurial flare had created stellar careers. In March 1999 he was appointed as managing Director and CEO of what he had helped make Australia's largest bank.

Ciccuto cut the figure of the transformational leader and adopted an aggressive growth strategy. One of the more spectacular acquisitions was the AUD \$4.6 b purchase of MLC which added funds management to the bank's increasingly multi faceted identity and an instant portfolio of AUD $\$ 52 \mathrm{~b}$ under management. Three years later the fund management arm had increased in value by $43 \%$. Mr Cicutto was at the time also leading a strategy to expand the NAB in the United Kingdom and the United States as part of a global vision.

In 2003/4 Mr Cicutto was Australia's highest paid banker, reportedly earning AUD \$7.77m. (Clegg 2004). However, in February of $2004 \mathrm{Mr}$ Cicutto was forced to resign effectively for a failure in transactional leadership. Traders in the bank's foreign exchange area had been making transactions that were outside the bank's guidelines on risk management. Instead of enforcing compliance with these standards there was an assumption that the culture would guide decision making. The forex traders turned out to be an aberrant sub culture that had not been appropriately controlled, leading to losses of AUD $\$ 360 \mathrm{~m}$.

A bank's reputation and public confidence depends on its ability to report the detail of financial transactions and balances with precision. It should have the data retrieval capacity that allows management to speak of cash amounts in precise terms. However, when the news of the forex scandal broke Mr Cicutto had to concede that he did not know the extent of the losses and was not being able to develop an accurate calculation until much later (Durie 2004).

This lapse had not been the only failure to set up systems to protect the bank. Much more significant had been an earlier loss of AUD $\$ 4 \mathrm{~b}$ after the bank had tried to set up a mortgage business in the United States. The losses here had also been caused by the failure to design and enforce risk management guidelines.

Business may prosper under transformational leadership and where performance is defined by growth, there is likely to be a strong identity between transformational leadership and growth outcomes. However, if instead we are to define performance in terms of an organisation's long term sustainability or operational effectiveness, then an ability to build and enforce robust systems that protect a company from danger is likely to become more valued. Bold new ventures need to be implemented with an eye to consolidation and maintenance after the growth spurt. Against these criteria for leadership outcomes, we are likely to be able to identify relationships between high levels of transactional leadership and performance.

An important implication of this argument is that transactional leadership needs to be seen as being a far more sophisticated process than the dull processes envisaged by Bass and Avolio. Transactional leadership may protect against loss, but for it to be accepted as a leadership for winners, it needs a boost to its image. One way to bring about such a boost is to focus on positive role models of very senior and successful transactional leaders and to use their example to develop a more sophisticated construction of transactional leadership. 
One model of the sophisticated transactional leader is Phil Koperberg, who is Commissioner (CEO) of the New South Wales (NSW) Rural Fire Service. Like Cicutto, Koperberg started from the bottom, joining the North Springwood, local Bush Fire Brigade in 1967. However, Mr Koperberg does not cut the figure of the charismatic leader as the picture below demonstrates. He looks like the archetypal public administrator - Bristow in a uniform. Yet his ability to control an organisation which is enormous, diverse, volatile and operationally dangerous marks him out as one of Australia's great leaders. Indeed, such is the public admiration for his ability to control emergency situations that both sides of politics have sought him out as a potential parliamentary representative, a temptation that he has so far resisted.

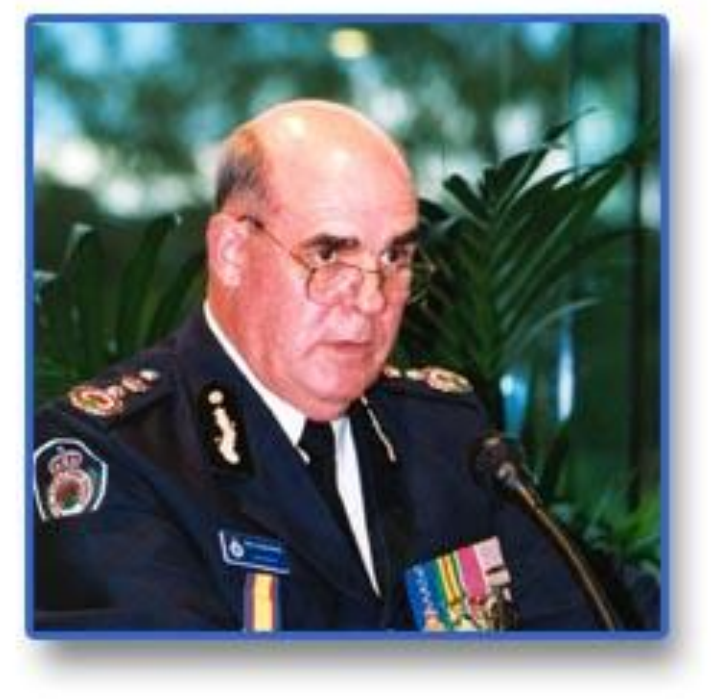

Koperberg came to prominence and showed his capacity for coordination and control in 1994 when over 800 fires erupted more or less simultaneously across NSW. 600000 hectares were destroyed and 4 people lost their lives in the fires. The scope of the disaster was way beyond the capacity of the NSW Rural Fire Service's resources. Yet Koperberg was able to marshal community resources and resources from other states and overseas to coordinate an effective response.

Koperberg's coordination capacity and ability to control large, desperate situations is not limited to fire fighting. In 1999 a devastating hail storm hit Sydney causing damage to approximately 30000 homes. The relevant relief authority is the State Emergency Service, but it immediately showed itself to be disorganised and unable to cope with the emergency. There were calls within a desperate community to bring in the Army, which might have effectively imposed martial law. (Lamont 2000) Instead the Government chose to ask Koperberg to clean up the mess and coordinate relief efforts.

Negotiating and marshalling resources is a task more aligned with transactional leadership than transformational leadership. Bad fire seasons occur approximately every eight years and a resource sufficient to combat a bad season cannot be maintained during the more comfortable years at the peak needed to meet the total need in the dire years. As such, the major challenge of the job is to create systems that can produce resources when and where they are needed. Koperberg has increased funding to the Rural Fire service by $75 \%$ since 1994 by convincing the Government to legislate to create a levy on rural property insurance, which provides a second major revenue stream and reduces the pressure on the public purse. 
When he took on the leadership role in 1985, local brigades were using World War 2 vintage blitz trucks and any other equipment that they could get their hands on. The Emergency Services Minister (in a rare moment for a politician) recently gave credit to Koperberg for building up the resource base to the point where new, modern trucks are in operation across the State. He also provided the following endorsement of Koperberg's leadership. "It is the Government's view that the RFS manages both the challenges of bushfires and its 65,000 volunteers in a manner unmatched by any fire service in the world. Phil Koperberg's leadership is part of the reason for this success." (Carlton 2003)

65000 volunteers have almost as many employers who lose their workers when the clarion call goes out to come to the fire. The problem is especially acute in Australia where most people are employed by small business. Not only does Koperberg need to constantly maintain the resource of the fire fighters, but must also maintain a network of public support which convinces employers to support the granting of leave without warning to attend fires. From time to time employers withdraw support and need to be gently cajoled back into the system.

A perennial problem in Fire Fighting in NSW, which had lead to inflexibilities in the use of resources, had been the long term antagonism between the Rural Fire Service (volunteers focused on bushfires) and the entirely separate Urban Fire Brigade (professionals focused on house and commercial property fires). For decades there had been unproductive demarcation arguments over what constitutes a village (the turf of the RFS) and what constitutes a town (the turf of the Urban Fire Brigade). In the past, urban fire fighters who were off duty were not allowed to assist bush fire fighting or provide equipment. Against this climate and history Koperberg built a relationship with the CEO of the NSW Fire Brigade which produced an agreement about mutual assistance and cooperation (Robinson and Noonan 2003).

After 1994 fires the State Coroner had criticised the structure of authority for fire fighting, which was based in Shire Councils, as fragmented and removing any chance of coordination of resources across the state. The Coroner effectively gave Koperberg a mandate to build centralised control, to develop a policing role and to improve the level of coordinating IT and fire fighting technology. Koperberg then set about the task of building a state wide corporate body that provided governance over 2200 separate local units.

Building centralised coordination capacity has created frictions within the overall structure. Volunteers are self reliant and resistant to change imposed by what they see as city based bureaucrats. To borrow Charles Handy's famous adage, providing governance and control to volunteer fire-fighters is rather like herding cats, except in this case, there are 65000 cats to be herded. Volunteers tend to be motivated by their own sense of service to the community and can not be coercively subjected to central control. For example, volunteers living around the state's borders are likely to act on their own volition, without checking with central office, and take their trucks to fires which are local from their perspective but across state borders from a central perspective.

Koperberg has been criticised for creating a central organisational apparatus which is militaristic, hierarchic and rank conscious. He has also been accused in parliament of being a political animal who intimidates others into submission and compliance (Karvelas 2003). In late 2004 local fire fighters ran a campaign through the media against expenditure on centralised coordination, using the highly symbolic claim that money was being spent on a new corporate headquarters when they had not been given new fire retardant boots since 1999 .

From time to time elements band together and threaten to split from the main body. This happened in 1999 when a number of meetings were held in various rural centres with the aim of setting up an alternative organisation and in 2004 when farmers set up an alternative Brigade in Peak Hill in central NSW. At such times the transactional leadership challenge is simply to put Humpty Dumpty back together. In contrast to the criticism of Koperberg as martinet, he achieved re integration through patient diplomacy: visiting the areas, listening to the concerns of the locals and deploying resources to meet their needs. 
The capacity to gain cooperation through the use of contingent rewards is another transactional leadership challenge which is a particularly acute in an organisation of unpaid volunteers. However, Koperberg is actively creating and providing arenas for tangible recognition. In particular, he provides commendations and ceremonial situations to reward the values of the fire service. At one such ceremony Koperberg recently gave an insight into what he sees as the meaning and purpose of such rewards. He says "These achievements are praised in front of their peers to create an environment where recognition, respect and praise are sought and encouraged, contributing to a culture of excellence."

Despite tensions across the culture and structure of the organisation, perennial resource problems and a limited ability to provide authoritative imposition of processes, Koperberg has managed to run the Rural Fire Service efficiently. Other emergency services and fire services operating other states are occasionally criticised for a lack of coordination and leadership by judicial and public authorities and the press (Corder 2003), but never NSW.

\section{CONCLUSION}

The leadership development and assessment package sponsored by Bass an Avolio has undoubted academic credibility. Its construct validity has been well validated. In addition, its superiority over transactional leadership predicting leadership performance has been demonstrated in a great deal of research literature. However, that literature validates transformational leadership primarily because it relates it to the kind of change focused leadership outcomes that transformational leadership is already well designed to achieve. The unfortunate consequence of all this validation is a widely accepted, globally franchised leadership assessment and development package that is being used by consultants and Human Resource Departments to reconstruct the nature of leadership. The package is behaviourally focused in as much as it specifies ideal behaviours and encourages subjects and their mentors to actually increase the frequency of desirable behaviours and decrease the frequency of undesirable behaviours. In other words leaders are being conditioned away from transactional behaviours and towards transformational behaviours. Transformational behaviours are being sought out and rewarded. However the fundamental message of earlier situational leadership theory is being forgotten. Many situations require sophisticated transactional leadership. The case studies outlined here are designed to show the danger of forgetting the transactional dimension of leadership (Cicutto). They provide a starting point to developing the idea of transactional leadership so that it can be seen in a more favourable light (Koperberg). The currently accepted construction of transactional leadership only needs be modified a little before it can be seen as vital to ensuring the sustainability and ongoing prosperity of organisations as well as a bulwark against disaster. Once given this more significant and attractive face, a better balance can be argued between the elements of transactional and transformational leadership.

\section{REFERENCES}

1. Avolio, B.J. (1996). What's all the karping about down under?: Transforming Australia's leadership systems for the twenty-first century. In K.W. Parry (Ed.) Leadership research and practice: Emerging themes and new challenges. Victoria: Pitman.

2. Barling, J., Weber,T., \& Kelloway, E. K. (1996). Effects of transformational leadership training on attitudinal and financial outcomes: A field experiment. Journal of Applied Psychology, 81 (6), 827-832.

3. Barratt, P., Hollway, S., \& Shergold, P. (1996). Improving APS leadership: A discussion paper prepared for the Portfolio Secretaries Retreat. Canberra: Australian Public Service.

4. $\quad$ Bass, B.M. (1990) The Bass \& Stogdill Handbook of Leadership: Theory, research and managerial applications. Third Edition. New York: Free Press

5. Bass, B.M. \& Avolio, B.J. (1993). Transformational Leadership: A response to critics. In M.M. Chemers, \& R. Ayman. (Eds.). Leadership theory and research: Perspectives and directions. Sydney: Academic Press Inc.

6. Bass, B.M. and Avolio, B.J. (1994) Improving organizational effectiveness through transformational leadership. Thousand Oaks, CA: Sage Publications

7. Bass, B.M. (1997). Does the Transactional-Transformational Leadership Paradigm Transcend Organisational and National Boundaries? American Psychologist, 52 (5), 130-139. 
8. Bass, B.M. (1998) Transformational leadership: Industrial, educational and military impact. Mahway, N.J.:Lawrence Erlbaum Associates

9. $\quad$ Blake R., and Mouton J., (1978) The New Managerial Grid Gulf, Houston

10. Carlton M., (2003) Ratbags Fail To Smoke Out Koperberg Sydney Morning Herald 26 July pg 26

11. Clegg, B. (2004) To be Frank it Doesn't Add Up Financial Review 17 January pg 64

12. Den Hartog, D. N., Van Muijen, J. J., \& Koopman, P. L. (1997). Transactional versus transformational leadership: An analysis of the MLQ. Journal of Organizational and Organisational Psychology, 70, 19-34.

13. Durie, J. (2004) Damning Insight Into NAB Financial Review 20 January pg 48

14. Feidler F., and Chemers M., (1984) The Leader Match Concept $\left(2^{\text {nd }}\right.$ ed) Wiley New York

15. Heifetz R., and Laurie D., The Work of Leadership Harvard Business Review December Vol 79 \# 11 pp131-141

16. Heresy P., and Blanchard K., (1988) Management of Organizational Behavior Prentice Hall Englewood Cliffs NJ

17. Howell, J.M., \& Avolio, B.J. (1993). Transformational leadership, transactional leadership, locus of control, and support for innovation: Key predictors of consolidated business unit performance. Journal of Applied Psychology, 78 (6), 891-902.

18. Karvelas P., (2003) Fire Chief Threat to his Troops The Australian 15 July pg 6

19. Kirkpatrick, S.A., \& Locke, E.A. (1996). Direct and indirect effects of three core charismatic leadership components on performance and attitudes. Journal of Applied Psychology, 81 (1), 36-51.

20. Kotter J., (1999) John P. Kotter on What Leaders Really Do Harvard Business Press, Boston

21. Lamont L., (2000) Emergency Service Waits for Gods to Act Sydney Morning Herald 7 April pg6

22. Lowe, K.B., Kroeck, K.G., \& Sivasubramaniam, N. (1996). Effectiveness correlates of transformational and transactional leadership: A meta-analytic review of the MLQ Literature. Leadership Quarterly, 7 (3), $385-425$

23. McNeese-Smith, D. (1996). Increasing employee productivity, job satisfaction, and organisational commitment. Hospital and Health Services Administration, 41 (2), 160-175.

24. Podsakoff, P.M., MacKenzie, S,B, \& Bommer,W.H. (1996). Transformational leader behaviours and substitutes for leadership as determinants of employee satisfaction, commitment, trust, and organisational citizenship behaviour. Journal of Management, 22 (2), 259-298.

25. Robinson M., and Noonan G., (2002) Deal Boosts Brigade Force After Union Complaint Sydney Morning Herald 5 January pg 4

26. Russ, F.A., McNeilly, K.M., Comer, J.M. (1996). Leadership, decision making and performance of sales manager: A multi-level approach. Journal of Personal Selling and Sales Management, 16 (3), 1-15.

27. Singer M. S. \& Singer, A. E. (1990). Situational constraints on transformational versus transactional leadership behaviour, subordinates leadership preference, and satisfaction. Journal of Social Psychology, 130, 385-396.

28. Wainwright R., (2004) Fire Chief Listens and 1300 Volunteers Get Their Boots Sydney Morning Herald 6 December pg1

29. Yammarino, F. J., Spangler, W. D., \& Bass, B. M. (1993). Transformational leadership and performance: A longitudinal investigation. Leadership Quarterly, 4, 81-102. 
Journal of Business \& Economics Research - November 2007

Volume 5, Number 11

NOTES 